\title{
CARTOGRAFIAS E CURRÍCULOS-MAPAS: ECOLOGIA EM ESPAÇOS EDUCATIVOS NÃO ESCOLARIZADOS
}

\author{
Angélica Vier Munhoz ${ }^{1}$ \\ Jane Mazzarino ${ }^{2}$
}

Resumo: Quando se pensa em romper com um tipo de pedagogia uniformizante para provocar novas formas de aprender e ensinar, também se torna necessário pensar em uma arquitetura curricular diferenciada, já que o modelo da escola regular formal demonstra não dar mais conta das demandas das novas gerações. Este artigo propõe pensar em espaços educativos não escolarizados, cujos currículos, mais abertos e não disciplinares, configuram-se em currículos-mapas e aponta a cartografia como instrumento de investigação, de descobertas e aprendizagens culturais, capaz de produzir modificações na prática pedagógica docente. Por fim, analisa a experiência realizada na disciplina Prática Investigativa III, do curso de Pedagogia do Centro Universitário UNIVATES/RS/BRA, cujo objetivo era criar uma prática educativa não escolarizada, a partir da cartografia dos movimentos de produção de um currículomapa, tendo como princípio curricular filosófico a relação com o meio ambiente.

Palavras-chave: Currículo. Cartografias. Espaços educativos não escolarizados.

\section{CARTOGRAPHIES AND MAPS-CURRICULA: ECOLOGY IN NON-SCHOOLED EDUCATIONAL SPACES}

Abstract: When we think about breaking up a certain standardizing pedagogy to raise new ways of learning and teaching, it also becomes necessary to think about a new differentiated curricular architecture since evidence shows the regular formal model of school does not cope with the demands of the new generations anymore. This paper proposes to think of non-schooled educational spaces, whose more open and nondisciplinary curricula are formatted into maps-curricula, as well as it points out cartography as an instrument of investigation, discoveries and cultural learnings, able to make changes in the pedagogical teaching practice. At last, it analyses the experience carried out in the subject Prática Investigativa III (Investigative Practice III) of the Faculty of Education/Pedagogy of Centro Universitário UNIVATES/RS/BR. The objective was to create a non-schooled educational practice starting from the cartography of the movements of a map-curriculum production, based on the relation with environment as a philosophical curricular principle.

Keywords: Curriculum. Cartographies. Non-schooled educational spaces.

\footnotetext{
${ }^{1}$ Doutora em Educação pela Universidade Federal do Rio Grande do Sul (UFRGS). Docente do Centro de Ciências Humanas e Jurídicas e dos Programas de Pós-Graduação - Mestrado em Ensino e Mestrado profissional em Ensino de Ciências Exatas do Centro Universitário Univates, Lajeado, Rio Grande do Sul, Brasil. angelicavmunhoz@gmail.com

${ }^{2}$ Doutora em Ciências da Comunicação pela Universidade do Vale do Rio dos Sinos (Unisinos). Docente do Centro de Ciências Humanas e Jurídicas e do Programa de Pós-Graduação - Mestrado e Doutorado em Ambiente e Desenvolvimento do Centro Universitário Univates, Lajeado, Rio Grande do Sul, Brasil.

janemazzarino@gmail.com
} 


\section{CARTOGRAFÍA Y CURRÍCULOS-MAPAS: ECOLOGÍA EN ESPACIOS EDUCATIVOS NO ESCOLARIZADOS}

Resumen : Cuando se piensa en romper con una especie de estandarización de la pedagogía para provocar nuevas formas de aprendizaje y enseñanza, también se hace necesario tener en cuenta una arquitectura curricular diferenciada, ya que el modelo de escuela regular oficial demuestra no llevar en cuenta las exigencias de las nuevas generaciones. En este artículo se propone pensar en espacios educativos no formales, cuyos planes de estudios, más abiertos y no disciplinarios, configuran currículosmapas, y apuntan a la cartografía como herramienta de investigación, descubrimientos y aprendizaje cultural, capaz de producir cambios en la práctica pedagógica. Por último, se analiza el experimento llevado a cabo en la disciplina Práctica de Investigación III, en el curso del Centro Universitario de Pedagogía UNIVATES/RS/BRA, cuyo objetivo era crear una práctica educativa no escolarizada, desde la cartografía de los movimientos de producción de un curriculum-mapa, teniendo como guía curricular filosófica la relación con el medio ambiente.

Palabras-llave: Currículo. Cartografía. Espacios educativos no escolarizados.

\section{Introdução}

O Curso de Pedagogia no Brasil, desde sua origem em 1930, tem, como sua maior finalidade, a formação do educador para atuar na educação formal, regular e escolar. Discussões sobre as novas demandas de trabalho e atuação em diferentes espaços educativos têm ocupado o debate da Pedagogia, sobretudo a partir da Reforma da Educação, em 1996, quando o currículo mínimo foi substituído por diretrizes curriculares, possibilitando a diversidade e diversificação de projetos educacionais. As diretrizes curriculares tensionaram novas configurações nos currículos de formação de professores, no entanto, as fragmentações por disciplinas, as ordenações do tempo e do espaço, o modelo da educação institucionalizada, reproduzem essa racionalidade.

Ainda que possa se pensar em diferentes pressupostos conceituais, o fato é que as teorizações contemporâneas nos levam a admitir que a crise da modernidade colocou em questão a linearidade da história, possibilitando rupturas de diversas forças: sociais, culturais, educativas, gerando uma imprevisibilidade no mundo das instituições.

No entanto, quando se pensa em romper com um tipo de pedagogia uniformizante para provocar novas formas de aprender e ensinar, também se torna necessário pensar em uma arquitetura curricular diferenciada, já que o modelo da escola regular formal demonstra não dar mais conta das demandas das novas gerações.

Este artigo pretende mostrar alguns caminhos percorridos no sentido de expandir a formação e atuação do pedagogo para além dos espaços formais da sala de aula regular. Propõe pensar em espaços educativos não escolarizados, cujos currículos, mais abertos e não disciplinares, configuram-se em currículos-mapas (GALLO, 2000). Também aponta a cartografia como instrumento de investigação, de descobertas e aprendizagens culturais, capaz de produzir algumas rupturas na prática pedagógica docente. Por fim, analisa a experiência realizada na disciplina Prática Investigativa III, do curso de Pedagogia do Centro Universitário UNIVATES/RS/BRA, cujo objetivo era criar uma prática educativa não escolarizada, a partir da cartografia dos movimentos de produção de um currículo-mapa, tendo como princípio curricular filosófico a relação com o meio ambiente. 


\section{A Pedagogia e os espaços educativos não escolarizados}

A educação, durante muito tempo, foi confundida com a escola, e ambas as palavras eram, inclusive, compreendidas como sinônimos. No entanto, enquanto a educação é um processo "que distingue o gênero humano a partir da faculdade da memória e da sua capacidade de construir ferramentas aliadas à vida em sociedade" (CORRÊA; PREVE, 2011, p.187), a escolarização é educação com objetivos institucionalizados, cujas ações buscam a "uniformização das mais diversas formas de sociabilidade e modos de vida ao recobri-lo com o véu da cidadania" (CORRÊA; PREVE, 2011, p.188). A escolarização é, portanto, um programa disciplinar, de controle e subjetivação, responsável pela condução do conhecimento.

Embora se perceba, ainda, um monopólio da escola sobre a educação, alguns movimentos são produzidos em direção às práticas educacionais que se dispersam por outros territórios e se configuram através de processos mais amplos e abertos.

O surgimento da educação não escolar é decorrente de vários fatores, entre eles, as mudanças ocorridas na estrutura familiar burguesa, as modificações nas relações de trabalho, as novas formas de produção numa sociedade em constante transformação do ponto de vista científico e tecnológico, produzindo antagonismos e desigualdades sociais. Além disso, observa-se um movimento de terceirização de funções específicas do Estado para as organizações não governamentais. Tais mudanças nas formas de vida desmontam a lógica tradicional com que a sociedade moderna estruturou e organizou a vida social e implicam na necessidade de uma reorganização. Quando a escola não consegue suprir as demandas sociais, torna-se necessária a criação de outras possibilidades educativas.

A educação é o modo como as pessoas, as instituições e as sociedades respondem à chegada daqueles que nascem. A educação é a forma com que o mundo recebe os que nascem, responder é abrir-se à interpelação de uma chamada e aceitar uma responsabilidade. Receber é criar um lugar: abrir um espaço em que aquele que vem possa habitar; pôr-se à disposição daquele que vem (LARROSA, 2001, p. 188).

As novas demandas socioeducacionais e culturais, então, ultrapassam os limites formais e regulares da escola, incorporando-se aos desafios relativos à formação do educador, já que são crescentes as intervenções e ações educativas em âmbitos, meios e organizações diferenciados do sistema educacional. As perspectivas de educação permanente e educação ao longo da vida também ratificam a necessidade de se discutir a educação além dos muros da escola.

Articular a educação, em seu sentido mais amplo, e engendrar a escola como apenas um dos territórios educativos, é uma urgência e uma demanda da sociedade atual. Os limites da educação formal, sobretudo nos moldes da escola moderna, explicitam a emergência de um olhar sociocultural para seu entorno. As novas demandas, portanto, são resultantes de processos educativos que se originam desvinculados da escola formal, embora possam se vincular à escola, desde que a mesma se abra às emergências de uma sociedade pedagógica.

Segundo Serres (1995), a sociedade da comunicação tornou-se, repentinamente, uma sociedade pedagógica, pois a sociedade inteira remodela-se a partir de uma mutação na espacialidade dos atos de ensino-aprendizagem, que, antes, se dariam em espaços de concentração e agora se encontram distribuídos em redes. Nesse sentido, não somente o ensino varia, mas também varia o que se ensina, como se ensina, onde se ensina, porque se ensina. A velocidade com que os conhecimentos e os saberes se modificam e os meios técnicos de que dispomos hoje, produzem uma mudança profunda na relação com os saberes e conhecimentos, necessitando de experiências profícuas que vão além do modelo curricular da escola formal, defasada de seu tempo. 
Assim, a educação não escolarizada produz outras formas de perceber e gerar os processos educativos: a relação com o conhecimento, as formas de produção dos saberes, a articulação do conhecimento com os saberes culturais, a valorização do vivido.

\section{Currículos-mapas}

Desde a Grécia Antiga, sobretudo com Platão, aprendemos a pensar por oposição, separação, hierarquização e classificação, cuja configuração arborescente, tem como característica pontos fixos, a partir dos quais surgem galhos ligados a um centro. Essa lógica arborescente e dual influenciou, em tal medida, a formação do pensamento ocidental, que é difícil pensar fora dela.

Tal lógica ganha ainda mais força com a hegemonização das ciências. Passa-se a priorizar a purificação dos saberes, quantificando e classificando dentro de um determinado campo, tudo o que pode ganhar estatuto de verdade. A disciplinarização surge dentro dessa racionalidade e é fruto de um arsenal tecnológico de conhecimentos que se efetua sobre a realidade. Como ilustram Deleuze e Guattari (1995, p.29), "No ocidente a árvore plantou-se nos corpos, ela endureceu e estratificou até os sexos".

A escolarização pressupõe um modelo linear e sequencial de currículo, produto desse paradigma epistemológico racional-positivista que se consolidou como hegemônico no pensamento ocidental, e acabou por definir os espaços/tempos da escola moderna, fundada na norma, sequência e disciplina e dissociado de seu contexto sociocultural. Os currículos são árvores: tem um ponto de origem, um centro, uma evolução, um desenvolvimento. Eles pedem raízes, um tronco condutor com ramificações organizadas e hierarquizadas.

Construída sob a égide dos princípios de fragmentação, homogeneidade e linearidade, essa racionalidade muito contribuiu para a formação e prática docente, limitadas a espaços fechados e serializados, à prescrição de conteúdos escolares, a uma percepção universalizante da realidade. Nesse sentido, a disciplinarização pedagógica é decorrência da disciplinarização epistemológica.

No currículo disciplinar, tudo pode ser controlado: o que o aluno aprende com que velocidade o processo acontece e assim por diante. Tudo pode ser avaliado: o desempenho do aluno, a 'produtividade' do professor, a eficácia dos materiais didáticos etc. Da mesma forma, todo o processo pode ser metrificado, e o desempenho do aluno traduzido numa nota, às vezes com requintes de fragmentação incorporados no número de casas decimais (GALLO, 2000, p.17).

Assim, a escola é tão disciplinar que nos parece impossível pensar em um currículo não disciplinar. No entanto, a ideia da transversalidade no currículo, abordada por Gallo (2000), pode ser pensada na produção e circulação dos saberes, desenhando um currículo não disciplinar.

Rizomático e nômade, o currículo não disciplinar dispensa uma raiz principal, pontos fixos. Ele é produzido como um mapa, em suas tentativas de experimentar caminhos investigativos, multiplicar sentidos, inventar conceitos. Suas múltiplas entradas permitem outras formas de movimento. O mapa, segundo Deleuze e Guattari (1995, p.22), "[...] é aberto, conectável, desmontável, composto de diferentes linhas, suscetível de receber modificações constantemente". O currículo-mapa é um composto de linhas e traçados que, dificilmente, sabemos onde inicia e onde termina. A sua força está no meio - lugar de ebulição, de invenção, de diferenciação.

No currículo-mapa é possível sentir - energias, potências, sensações - ao experimentar outros pensares, mapear outras paisagens, desconstruir certezas, desmanchar verdades. Nele, os conhecimentos são expandidos, os espaços de criação alargados, os sentidos multiplicados. 
Seus agenciamentos são sempre culturais, pois os atores de um currículo-mapa estão centralmente envolvidos na produção do social. Dessa forma, o currículo-mapa se aproxima dos modos de fazer da educação não escolarizada.

As verdades e os valores da educação são problematizados no currículo-mapa. Afinal, não importa mais saber se determinado conteúdo é verdadeiro ou falso, mas saber os processos, a produção, o funcionamento. Por que tais verdades? Tais conhecimentos? Por que queremos formar um tipo de sujeito? Como afirma Silva (2003, p.55), "um currículo é sempre uma imposição de sentidos, de valores, de saberes, de subjetividades particulares".

\section{0 educador-cartógrafo e os territórios não escolarizados}

A cartografia remete a um território espacial, cujas transversalizações abandonam fronteiras disciplinares, ativando saberes locais, espaços e tempos variados, velocidades diferenciadas, fluxos, paisagens desconhecidas. Busca-se, por meio da cartografia, mapear os processos, os acontecimentos que atravessam a vida sempre povoada de sonhos, desejos, sensações e afetadas por intensidades.

A cartografia é um mapa feito de linhas, um plano de velocidades e intensidades. A linha não preexiste, é preciso traçá-la e, ao traçá-la, permite-se voar, viajar, evadir, fugir. Traçar uma cartografia é criar rizomas e não raízes. Mapear significa acompanhar os movimentos, os processos de invenção e de captura que se expandem e se desdobram no momento em que o mapa é projetado. Cartografar, portanto, é estar atento às formas com que o desejo se expande no campo social, não importando os critérios de verdade ou juízos de valor.

Sendo assim, a investigação cartográfica diferencia-se de outros procedimentos metodológicos por não ser possível separá-la da vida que pulsa, das relações, dos afetos. Quer captar a vida onde ela está acontecendo, nas pessoas e nos grupos, nos seus territórios, onde eles vivem, aprendem, vibram, se relacionam, produzem.

Cartografar os movimentos de produção do currículo, suas rotas, na perspectiva de uma pedagogia, pode ser um valioso instrumento de investigação, de descobertas e aprendizagens culturais, produzindo, também, modificações na prática pedagógica docente. Os diversos territórios, ao serem cartografados, permitem localizar interesses, afetos, dispositivos que são potencializadores de aprendizagens ou não, ampliando a percepção do educador sobre o universo pedagógico que ajuda a criar.

Nesse processo, o educador-cartógrafo torna-se um pesquisador sempre curioso, aberto a perceber a vida, o movimento dos seus alunos, as intensidades que acontecem na escola, aquilo que impede o desejo de aprender, as singularidades entranhadas nas subjetividades. Ao deixar-se afetar por essas descobertas, o educador incorpora, em sua prática docente, o desejo, as potencialidades de seus alunos, tornando-se cúmplice de seus processos pedagógicos. Rolnik $(1989$, p.06) nos provoca:

Restaria saber quais são os procedimentos do cartógrafo. Ora, estes tampouco importam, pois ele sabe que deve 'inventá-los' em função daquilo que pede o contexto em que se encontra. Por isso ele não segue nenhuma espécie de protocolo normatizado.

A cartografia, portanto, não opõe pesquisa e intervenção, teoria e prática, pois conhecer para o cartógrafo pressupõe implicar-se com o mundo, comprometer-se com a sua produção. Nesse sentido, é preciso que o pesquisador esteja engajado na realidade a ser conhecida, que compartilhe de um mesmo território existencial das pessoas da determinada realidade investigada. Para Alvarez e Passos (2009, p.135), "cartografar é sempre compor com o território existencial, engajando-se nele". Constrói-se, assim, o conhecimento com e não sobre o campo pesquisado. 
Nesse sentido, a cartografia possibilita que novas formas de aprendizagem possam ser percebidas e geradas, que outros espaços pedagógicos sejam criados. Os envolvidos no processo pedagógico deixam de ser somente atravessados pelos acontecimentos para se perceberem como produtores de movimentos no território, capazes de produzir novas realidades. Foi esse o desafio lançado para uma turma de alunos da disciplina Prática Investigativa III, do curso de Pedagogia do Centro Universitário Univates.

\section{A educação ambiental e as possibilidades abertas para os currículos-mapas}

Vive-se uma transição de paradigmas, entre uma abordagem naturalista para a política, e desta para a estética. No âmbito das propostas políticas, uma análise conjunta de documentos brasileiros norteadores da educação ambiental, que incluiu a Política Nacional de Educação Ambiental (PNEA), os Parâmetros Curriculares Nacionais (PCNs) que tratam do Meio Ambiente, o Programa Nacional de Educação Ambiental (ProNEA) (BRASIL, 1999; BRASIL, 1997; BRASIL, 2003) e, também, escritos de autores como Santos e Jacobi (2010), Loureiro (2002) e Lima (2002) apontam que, hoje, é hegemônica a proposta da educação ambiental a partir do paradigma político-emancipatório. Basta uma análise do discurso dos fragmentos apresentados nos documentos e nas obras de autores dessa vertente para perceber a força de sentidos como: conflito, apropriação, democracia, participação, dialogia, consciência crítica, resolução de problemas, ação para mudanças, responsabilização, agir na história, compromisso social, formação de cidadãos conscientes, empoderamento, protagonismo (MAZZARINO, 2015)

No entanto, marcas de uma proposta que privilegia elementos estéticos, ainda marginal na educação ambiental, podem ser encontradas ao se tatear os mesmos documentos e escritos de outros autores, como Barcelos (2003), Godoy (2007), Passetti (2007), Mendonça (2012) e Silveira (2009). Uma análise do discurso dessa vertente, denominada por Mazzarino como poética, privilegiam forças outras: vivenciar, afetividade, subjetividade, imaginário, vínculo, sensibilidade, emoção, arte, sensações, corpo, expressar, compartilhar, escuta poética, acaso, temporalidades humanas não lineares, derivas, ecologias menores, fragilidade, intuição, arriscar-se, mover-se sem mapa, escuta dos desejos, silêncios, conversação, viver solidário e amoroso, mergulho na natureza, contato direto, abrir-se à percepção, buscar o incerto e o curioso, afloramento de dimensões adormecidas, experiência sensível, redescoberta do potencial criativo. São sentidos que se conectam com a proposta cartográfica para possibilitar novas formas de aprendizagem, tanto em espaços pedagógicos escolares como não formais, o que foi possível observar a partir dos relatos que seguem.

\section{Cartografias de uma prática educativa não escolarizada}

Em uma sala de aula de 25 alunos, da disciplina de Prática Investigativa III do Curso de Pedagogia, do Centro Universitário UNIVATES/RS/BRA, a professora propõe aos alunos criar uma prática educativa, não escolarizada, a partir dos conceitos e tensionamentos acerca do currículo e da noção de currículo-mapa. Nesse sentido, a proposta não poderia configurarse em um programa disciplinar. Além disso, um princípio deveria ser levado em conta nessa tarefa de criação: a relação com o meio ambiente.

É importante dizer que essa disciplina é continuidade de outra (Prática Investigativa II), cujo objetivo era conhecer diferentes espaços educativos não escolares (organizações não governamentais, hospitais, presídio, movimentos sociais etc.), no sentido de experienciar 
outras situações de aprendizagem fora do espaço regular e formal da escola ${ }^{3}$. Os alunos, portanto, eram instigados a se defrontar com um nicho de possibilidades de experiências educativas e perceberem que, por menor ou pior que fosse a infraestrutura do espaço educativo e das condições de vida de uma determinada população, havia, ali, um espaço aberto a intervenções, um lugar para criação, que escapava aos espaços canonizados e formatados das salas de aula tradicionais (MUNHOZ, 2012).

Pois bem, agora o desafio era outro. Cartografar uma paisagem. Criar um espaço onde a aprendizagem ocorresse fora dos moldes do currículo linear, com tempos dilatados, espaços abertos, saberes expandidos. Para isso, fazia-se necessário pensar e criar uma prática, definir a população (crianças, adolescentes, terceira idade etc.) propor um lugar onde essa prática poderia ser realizada, imaginar o seu funcionamento, compor um currículo não escolarizado, articular as questões pedagógicas. Além disso, essa instituição deveria ter como princípio a relação com o meio ambiente. Para Tristão (2001, p.2):

A dimensão ambiental configura-se como um fator mobilizador, atribuído ao seu poder de partilhar, agregar com diferentes atores e atrizes os mais diferentes contextos e ações com princípios éticos e humanistas numa perspectiva que transcende fronteiras. Sem qualquer pretensa hierarquia, transforma-se em uma questão vital, inter-relacionada com todas as outras dimensões.

Guattari (1991) afirma que para se esclarecer as questões relativas à destruição do meio ambiente global e à ameaça da raça humana no planeta, torna-se necessária uma articulação ético-política entre três registros ecológicos: ambiente, relações sociais e subjetividade, que ele chamou de ecosofia.

Segundo Guattari (1993), os maiores problemas ecológicos são decorrentes de lógicas binárias oriundas da modernidade, que geram uma homogeneização universalizante e reducionista das subjetividades. Em uma proposta ecosófica, as pessoas tendem a se tornar mais solidárias e singulares.

É nesse sentido que se pode pensar em uma ecopedagogia rizomática, fluida, que abandona a ideia do conhecimento como construção arborescente, cujos fundamentos estão baseados em raízes profundas, e torna os campos dos saberes abertos, buscando escapar às formas de controle.

Escolas e ambientalistas trabalham com o que Godoy (2007, p. 123-125) denomina "ecologia maior", baseada no controle de comportamentos considerados "socialmente danosos". Os corpos, nesse contexto, tanto o individual quanto o da Terra, estão para serem formados ou (re)formados segundo prescrições de regulação cada vez mais inclusivas e democráticas sobre o que "se deve ou não fazer, no que se pode ou não fazer". A autora não nega a escola, a ecologia ou o ambientalismo, mas propõe menores ecologias.

Sem sentido ou finalidade, elas não reconhecem qualquer ordem, qualquer razão, qualquer estabilidade. Remetem, sobretudo, àquilo que na vida permanece indomesticável, escapando insistentemente aos sistemas de ordenação, sejam eles quais forem, utilizados para subsumir a instabilidade, o desequilíbrio sob a forma do conjunto acabado e harmonioso, repositório dos sentidos e das finalidades, em relação ao qual cada um está ao serviço. Um ruído permanece insistentemente, mesmo em face dos mais arrojados projetos de pacificação impostos à vida e ao pensamento; esta é a força do menor, ou a potência minoritária [...] Cabe-nos, portanto, dar ou não passagem ao que insiste.

\footnotetext{
${ }^{3}$ Essa experiência foi relatada em: MUNHOZ, Angélica V. Práticas Investigativas: dos espaços aos saberes. Revista Interacções. Portugal, 2012, n. 21.p. 190 -203
} 
A natureza fluida da educação ambiental também é percebida por Sato, Gauthier e Parigipe (2005, p. 112) quando afirmam que essa área "encerra um espaço híbrido em constante movimento". Portanto,

[...] deve ser historicamente acumulada e densamente transgressora, para que as múltiplas racionalidades se encontrem com a paixão, o brincar e a imaginação nos seus desejos de renovação e dialoguem com as ancestralidades que os ventos, os rios e os mares escrevem nas paisagens [...].

Assim, no contexto de uma educação não escolarizada, não seria necessário definir valores prévios, criar novas verdades, mas, sim, possibilitar as conexões entre os diversos saberes, criar diálogos entre as culturas, resistir a concepções totalizantes. Além disso, se torna necessário voltar-se para o mundo ao redor e aos pequenos saberes dos membros da cultura local, apostando em uma educação dos sentidos, como propõe Duarte (2004, p.181). Essa educação refere-se a

[...] uma vida mais plena, prazerosa e sabedora de suas capacidades face à nossa ligação com os outros e as demais espécies do planeta. Este talvez consista hoje no objetivo mais básico e elementar de todo e qualquer processo educacional, por mais especializado que ele possa parecer.

A educação deveria possibilitar que se varie o modo de perceber o mundo. Para isto é preciso que se esteja atento aos estímulos dos sentidos, o que se refere a uma educação estésica e não anestésica, como a educação tradicional vem percorrendo. Para Duarte (2004, p.189) a educação deve ser uma "educação da sensibilidade humana", o que depende de uma nova visão acerca das relações humanas com o planeta. $\mathrm{O}$ autor afirma que é preciso

[...] adquirir a sensibilidade necessária para se comover com a natureza e, assim, senti-la parte integrante e indissolúvel de nossa existência, precisa, deste modo, principiar no treino dos sentidos para com o mais prosaico e urbano cotidiano de todos nós [...] Vale dizer: a descoberta do mundo natural e a consciência do quão ligados a ele estamos, por mais urbana seja a nossa vida, começa pelo aguçar de nossos sentidos, pelo seu desenvolvimento e sua apuração no dia-a-dia em que se vive, do qual faz parte, primordialmente, o espaço compreendido entre os muros da escola e os de nossa casa, bem como toda a paisagem da cidade pela qual nos movimentamos (DUARTE, 2004, p.189).

A educação pode convidar à apropriação, exploração e coexistência com a natureza, sem pretender dominá-la ou negá-la, mas entregando-se a um viver matríztico, baseado no respeito e na colaboração na criação de um mundo que admita o erro, que permita viver a responsabilidade pelas consequências de nossas ações e refletir sobre o que nos acontece, percebendo sua interdependência com a realidade. É o que nos diz Maturana (1998). É preciso dar-se conta que, como afirma Maturana (1998, p.53), "nossa corporalidade nos constitui, e que o corpo não nos limita, mas ao contrário, nos possibilita". Aprender é transformar a corporalidade, que se modifica a partir da história das nossas interações. Mudamos a partir de nossas interações, e assim o mundo se transforma. Maturana explica que, nesse sentido, nada é trivial ou irrelevante, já que o que pensamos e fazemos têm consequências no domínio das mudanças estruturais a que pertencemos.

O autor reclama a valorização das emoções entrelaçadas no cotidiano como constituintes do viver humano e de todo sistema racional. Para Maturana (1998, p.15), "emoções são disposições corporais dinâmicas que definem os diferentes domínios de ação em que nos movemos". O caos não se instala com a inserção da emoção no sistema racional, mas quando perdemos nossa referência emocional, encontrando-nos recorrentemente em emoções contraditórias, diz o autor. Para ele, é a aceitação do outro, o compartilhamento, a convivência no amor que caracteriza as relações sociais, nos diferencia dos animais, move a 
história humana desde seu início e é a condição necessária para o desenvolvimento físico, psíquico, social e espiritual.

Dessa forma, o cotidiano desses espaços educativos não escolarizados, que desafiamos para que fossem construídos pelos educandos da disciplina Prática Investigativa III, deveria ter uma dinâmica própria, aberta às possibilidades e configurações da sociedade contemporânea e às novas práticas pedagógicas. Desenvolvidos em currículos-mapas, não disciplinares, a ideia era construir um processo de singularização da aprendizagem a partir das relações coletivas, das subversões e desconstrução de conceitos e representações. As práticas de aprendizagem deveriam ter, portanto, uma dimensão pessoal e coletiva, tendo como base a ampliação de sentidos plurais e diversos.

Ao escolher um local para a criação do projeto, os alunos-cartógrafos precisavam ter uma escuta atenta para aquela realidade, estar abertos a perceber quais os desejos daquela comunidade, deixar-se afetar pelas descobertas, pelos contatos, pelas sensações. Deixar-se atravessar pelos acontecimentos, a fim de produzir um novo possível.

Os resultados foram surpreendentes e criativos. Os projetos de invenção de espaços educativos agregavam os conceitos trabalhados e rompiam com os modelos lineares e disciplinares de currículos. Esses espaços não contavam com quadro negro, giz, salas de aulas formais, livros didáticos, mas eram, sem dúvida, espaços de aprendizagem. Além disso, contemplavam, claramente, em suas propostas pedagógicas, a preocupação com a ecosofia. Ainda foi possível perceber uma escolha pelo trabalho com oficinas. A possibilidade de trabalhar com oficinas coloca em cheque as relações hierarquizadas com o saber e propõe outras relações com os saberes, com a verdade e o poder, com o tempo e o espaço e as posições professor-aluno. Como diz Corrêa (1998, p.46):

A oficina é tomada como ação educativa em si, e não como meio para melhorar a aula, para produzir aulas mais interessantes, nem como estratégia didática e pedagógica adaptável à escola, a oficina abre-se como um campo de pesquisa autônomo de pesquisa em educação.

Neste artigo relatamos três projetos vivenciados pelas alunas-cartógrafas. O primeiro referia-se a uma organização não governamental itinerante, que funcionava em um ônibus, cujo currículo era composto por um conjunto de saberes e práticas voltadas para a discussão e preservação do ambiente. O ônibus, equipado com módulos educativos, circularia por um pequeno município, atendendo as crianças de uma comunidade no turno inverso ao da escola. Com dias fixos semanais em cada bairro, as crianças esperariam a sua chegada e ficariam envolvidas com as atividades ao longo daquele turno. Os materiais estariam disponíveis no ônibus para que oficinas, como produção de sabão a base de óleo vegetal, artesanato com reaproveitamento de material, bricolagem com embalagens, oficinas de leitura e outras tantas fossem inventadas pelas crianças.

Assim, pela via do trabalho com oficinas, a ideia de transversalidade se fazia presente nessa proposta educativa. As alunas sabiam que o mais importante seria aquilo que se passaria entre os grupos, nos grupos, entre as oficinas ou no atravessamento delas. E, mais do que qualquer resultado, buscavam mapear o quanto os grupos mergulhariam no plano da experiência, onde conhecer e fazer se tornam inseparáveis.

Um segundo grupo de alunos-cartógrafos criou um espaço educativo em um hospital, com o objetivo de promover a aprendizagem com crianças que permaneciam por um longo período hospitalizadas ou, devido às suas patologias, permaneciam por curtos períodos no hospital, mas retornavam frequentemente. Como pensar em um currículo em que as crianças são itinerantes? Um currículo com espaços e tempos flexíveis, com saberes que não seguem a lógica linear, tal foi o desafio desse grupo. Além disso, foi preciso levar em conta as limitações físicas e fragilidades dessas crianças. O projeto do currículo nesse espaço 
educativo não escolarizado previa cartografar os movimentos dessas crianças, as suas ausências da escola regular, o contato com a professora e com a família, inventando um fazer pedagógico cuja força encontrava-se nas conexões, nos entremeios de espaços e tempos, nos afectos que ali eram potencializados. Oficinas lúdicas, recreativas, pedagógicas foram pensadas a fim de produzir uma aprendizagem da diferença. Novamente aparecia a proposta de oficina enquanto possibilidade de escapar de uma aula formal. Para Corrêa e Preve (2011), a escolha de trabalhar com oficina é da ordem do desejo, de trabalhar com o que se gosta, com o que lhe afecta.

Um dos pontos mais importantes da oficina como estratégia em educação, é a ligação do oficineiro com o tema que escolhe. Uma oficina corresponde sempre a um interesse do oficineiro. Interesse que independe das obrigações que possa ter com o cumprimento de currículo ou por força de sua formação (CORRÊA; PREVE, 2011, p. 197).

No entanto, as alunas sabiam que nesse projeto nada poderia estar definido à priori, pois na cartografia, afirma Kastrup (2009, p.32), "não se busca estabelecer um caminho linear para atingir um fim". Expectativas, rotas e conhecimentos universalizantes deveriam ser deixados na porta de entrada. Era possível, sim, estabelecer algumas pistas com o objetivo de descrever, discutir, coletivizar as experiências. Além disso, seria preciso estar implicadas na realidade investigada e comprometidas com as experiências ali vividas.

Para tal experimentação, as alunas-cartógrafas sabiam, também, que necessitariam estar afetivamente engajadas, pois só assim poderiam habitar o universo do aprendizado das crianças hospitalizadas. Uma atenção flutuante, aberta e movente seria, portanto, capaz de rastrear as mudanças, os ritmos, as dificuldades, os processos vividos e experienciados pelo grupo cartógrafo-crianças hospitalizadas.

Embora essa experiência não tenha tido nenhuma relação direta com a prática ambiental, podemos pensá-la sob a ótica da ecosofia de Guattari (1991), como um modo de perceber a vida em suas relações com o meio, com o socius e com a subjetividade. A combinação dessas relações comporia uma ética da vida.

A certeza da percepção da existência, por parte de um indivíduo, deve estar atrelada ao fato de ser percebido pelo outro existente, que, por sua vez, necessita dessa mesma percepção. Assim, a possibilidade de compreensão do todo se dá quando cada um tem consciência de que, embora singular, é parte desse todo.

Ainda um terceiro projeto, importante de ser relatado, sobretudo porque o mesmo nasceu na disciplina Práticas Investigativas III, mas diferente dos outros, saiu do papel e ganhou existência real. O projeto Camaleão, criado por uma aluna da Pedagogia, iniciou, portanto, a sua idealização nessa disciplina. Os depoimentos presentes neste artigo foram coletados por meio de entrevistas e a partir do projeto apresentado pela aluna na disciplina. A aluna-cartógrafa relata:

A ideia de fundar um projeto de nível social surgiu na disciplina Prática Investigativa III, cursada no Curso de Pedagogia do Centro Universitário Univates. Depois de muitas visitas a diversos centros de educação formal e informal, inclusive a projetos sociais, fiquei tão entusiasmada com o que vi que percebi que aquele era o meu chão. Iniciei uma reflexão sobre a possibilidade de criar um projeto social em minha cidade. Após alguns estudos vi o termo 'cidade' um tanto amplo para a tal realização.

Para Vargas (2009), proporcionar aos pequenos e grandes moradores do bairro momentos de lazer, de exploração de habilidades, de enriquecimento da cultura, de conhecimento e de partilha mútua, promovendo, assim, a amizade, o companheirismo e a troca de experiências, tornou-se, portanto, o objetivo do projeto. 
Com o auxílio de alguns voluntários o bairro foi percorrido casa a casa, a fim de diagnosticar as necessidades e interesses dos moradores da localidade. Foram realizados diálogos e anotações junto às famílias, conta a aluna:

Percorri casa a casa no mês de janeiro conversando com os moradores e coletando os dados sobre suas vontades. Me frustrei muito, pois muito do que eles queriam era grande demais para as minhas possibilidades. Mas, uma das prioridades era $\mathrm{o}$ trabalho com crianças no turno oposto ao da escola, já que estas ficavam nas ruas.

Conhecer uma realidade é também criá-la. Acompanhar os movimentos, estar atento ao desejo que se expande no campo social, participar e intervir nas mudanças de determinado grupo é habitar um plano coletivo de forças que gera efeitos na produção de subjetividades e na transformação das relações micro e macropolíticas de um determinado território social. Segundo Passos e Barros (2009, p.30), "conhecer é, portanto, fazer, criar uma realidade de si e do mundo, o que tem consequências políticas".

Assim, em uma comunidade pequena, inicialmente sem local fixo, contando somente com voluntários, o projeto ganhou vida. Semanalmente, nos sábados à tarde, comunidade e voluntários passaram a se reunir em um local do bairro para a realização de oficinas: contação de histórias, pinturas, atividades com material reciclado, sessões de cinema, passeios, atividades recreativas... "E tudo foi se encaixando, convidei amigas para ajudarem nas oficinas com as crianças, a associação de bairros cedeu a creche e um campo de futebol para os trabalhos", descreve a aluna-cartógrafa.

Os espaços coletivos são territórios de fazer juntos. Ao fazer e inventar coisas nos reinventamos ao mesmo tempo. Para Kastrup (2008), o espaço da oficina é um espaço de aprendizagem inventiva, de invenção de si e do mundo. As pessoas se relacionam com os materiais flexíveis, recicláveis, capazes de transformação e criação, além de se relacionarem com outras pessoas, produzindo mutações nas relações com o socius. Distintos do processo de escolarização, as práticas de oficinas tornam-se "não mais um sistema identificável, apreensível, avaliável, mas cujos efeitos se fazem sentir na capacidade de desmontar tentativas de docilização para a produção de homens úteis" (CORRÊA; PREVE, 2011, p. 198)

O território vai sendo explorado por olhares, escutas, sensibilidades, gostos e ritmos. O acompanhamento do processo do próprio projeto vai dependendo de uma atitude, não está garantido de antemão. Ele requer aprendizado, atenção permanente, práticas coletivas. Podemos observar tal processo no relato da aluna:

E o projeto foi andando. Muitas portas se abriram para nós enquanto projeto e muitas se fecharam. As maiores dificuldades encontradas no caminho foram a falta de voluntários para trabalhar com as crianças, pois todo mundo anda ocupado demais para se doar para uma obra social, e a falta de recursos financeiros para manter o projeto.

A experiência de criação possibilita, ao mesmo tempo, uma experiência de autocriação. Ela tensiona, movimenta, nos desloca para outro lugar, produz novos agenciamentos e afectos. Implica em uma aposta ético-política, pois ao potencializar a vida, abre, também, a novos problemas que continuarão exigindo uma mudança de si e do mundo. “O projeto Camaleão é em minha vida um dos maiores sonhos já realizados”, diz a alunacartógrafa.

Dessa forma, destacamos alguns movimentos que emergiram em meio a essa disciplina, cujo intuito não era implantar uma nova verdade, mas experimentar algumas práticas não escolarizadas que pudessem, por um lado, problematizar o currículo disciplinar e por outro, pensar em outras configurações de currículos, mais abertas, plurais e conectáveis.

\section{Conclusão}


$\mathrm{O}$ artigo buscou discutir algumas práticas não escolarizadas que surgiram a partir de um espaço escolar instituído, como é o caso da universidade. Acredita-se que, mesmo dentro de um espaço escolar formal, é possível buscar formas alternativas para trabalhar com os alunos, rompendo com a lógica estruturante e hierarquizada do currículo escolarizado, como foi o caso do trabalho de oficinas criadas pelas alunas.

Percebe-se, assim, que os movimentos, as passagens e as trocas de saberes podem configurar-se através de aprenderes desvinculados de resultados, de significações, reduzidas por ações pedagógicas. Em tal perspectiva, a proposta de práticas não escolarizadas é também "um esforço de oposição e de luta contra a coerção de discursos teóricos, unitários e formais, através do reconhecimento de saberes locais, menores, ativados contra a hierarquização científica do conhecimento e de seus efeitos intrínsecos de poder".(FOUCAULT, 2004, p.172)

Essas práticas curriculares emergem, provocando nos envolvidos o que Leff (2011, p.47) denomina de "diálogos de saberes, que valoriza saberes errantes, ciganos, nômades", forjando valores que rompem com a lógica mercantil que se impõe a todas as áreas, fragmentando o conhecimento. Esses diálogos valorizam os aspectos ontológicos, as diferenças, a criatividade, a transformação, a hibridização, a autonomia, a justiça social e a qualidade de vida. Portanto, implicam em rompimentos com racionalidades lineares, processos homogêneos e reprodutivistas, e abrem-se para novos sentidos e práticas cotidianas, o que no campo da educação provoca tessituras nos pontos de contatos entre os diferentes saberes, em um currículo que se faz transversal.

E isto é tão possível quanto necessário, mesmo quando se observa que essas práticas não escolarizadas não dispensam algumas sistematizações para firmar pactos entre os sujeitos do processo educativo: o dia do ônibus da organização não governamental itinerante (tempo), o hospital e a associação como lugar de encontro (espaço). É necessário um plano mínimo de ação para desencadear os movimentos rizomáticos que se transformam em cartografias ecoeducativas ou de outras naturezas pedagógicas. Não se trata, portanto de uma ação sem direção, muito menos de um plano de orientação prescritivo com regras prontas e objetivos pré-estabelecidos. As diretrizes cartográficas em um currículo-mapa se fazem por pistas que orientam o percurso que agencia sujeito e objeto, teoria e prática em um mesmo plano de experiência.

Traçar uma cartografia, então, é propor um saber que se põe para ser movimentado, para, em seus deslocamentos, gerar outros e novos saberes. E nesses fazeres, é também necessário compreender como se dão as relações de poder no contexto em que se criam cartografias, já que os saberes locais não são isentos, mas emergem do contexto cultural em que são forjados, portanto, ainda fortemente marcados pela racionalidade burguesa, legitimada, hierárquica, entranhada nos corpos.

Fica dessas experiências de práticas investigativas realizadas a partir de uma disciplina universitária, que em meio a um currículo, onde tudo já está organizado, se pode seguir outros rumos e escapar ao planejado. Para isso, há de se dispor a perder os mapas, arriscar-se a uma viagem sem percursos definidos e sem ponto de chegada. Vive-se, então, em um currículo, as mais simples e intensas experimentações: partilham-se afectos e desejos, geram-se possibilidades de aprendizagens em contextos desconhecidos, prolifera-se a diferença, fica-se à espreita da multiplicidade do pensamento e da diversidade dos modos de estar no mundo.

\section{Referências}

ALVAREZ, J.; PASSOS, E. Cartografar é habitar um território existencial. In: PASSOS, E., KASTRUP, V. e ESCÓSSIA, L. (Orgs.). Pistas do método da cartografia: pesquisaintervenção e produção de subjetividade. Porto Alegre: Sulina, 2009. 
BARCELOS, V. H. de L. Educação ambiental e literatura: a contribuição das ideias de Octávio Paz. In: NOAL, F. O. BARCELOS, V. H. de L. (Orgs.). Educação ambiental e cidadania: cenários brasileiros. Santa Cruz do Sul: Edunisc, 2003. p.23-56..

BRASIL. Secretaria de Educação Fundamental. Parâmetros Curriculares Nacionais: Meio Ambiente/Saúde. Secretaria de Educação. Brasília: MEC, 1997. Disponível em: <http://portal.mec.gov.br/seb/arquivos/pdf/livro091.pdf>. Acesso em: 1 dez. 2013.

BRASIL. Lei $n^{\circ}$ 9.795, de 27 de abril de 1999. Dispõe sobre a educação ambiental, institui a Política Nacional de Educação Ambiental e dá outras providências. Brasília: Casa Civil, 1999. Disponível em: 〈http://www.planalto.gov.br/ccivil_03/Leis/L9795.htm>. Acesso em: 14 jun. 2010.

BRASIL. Programa Nacional de Educação Ambiental (ProNEA) 2003. Disponível em: <http://www.mma.gov.br/estruturas/educamb/_arquivos/pronea3.pdf > Acesso em: 22 nov. 2015.

CORRÊA, G. C. Oficina: apontando territórios possíveis em educação.1998 104f. Dissertação (Mestrado em Educação) - Universidade Federal de Santa Catarina, Florianópolis, 1998.

CORRÊA, G. C.; PREVE, A. M. H. A educação e a maquinaria escolar: produção de subjetividades, biopolíticas e fugas. Revista de Estudos Universitários, Sorocaba, v. 37, n.2, p. 181-202, dez. 2011.

DELEUZE, G.; GUATTARI, F. Mil Platôs: Capitalismo e esquizofrenia.Vol. 1 Rio de Janeiro: Ed. 34, 1995.

DUARTE JR. O sentido dos sentidos: a educação (do) sensível. Curitiba: Criar Edições, 2004.

FOUCAULT, M. Microfísica do poder. Rio de Janeiro: Graal, 2004

GALLO, S. Disciplinaridade e transversalidade. In: ALVES-MAZZOTI, A. J. et al. Linguagens, espaços e tempos no ensinar e aprender. Rio de Janeiro: DP\&A, 2000. p. 165 180.

GODOY, A. Conservar docilidades ou experimentar intensidades. In: PREVE, A. M. CORREA, G. (Org.) Santa Maria: Ed. da UFSM, 2007. p. 121-138.

GUATTARI, F. As três ecologias. Campinas: Papirus,1991.

GUATTARI, F. Caosmose: um novo paradigma estético. Rio de Janeiro: Editora 34, 1993.

SANTOS, V. M. N. ; JACOBI, P.R. Formação de Professores no Estudo do Ambiente: Construção do olhar Geocientífico e Cidadania. Anais do V Encontro da Associação Nacional de Pós Graduação e Pesquisa em Ambiente e Sociedade (ANPPAS), UFSC, Florianópolis, 2010. Disponível em: <http://www.anppas.org.br/encontro5/cd/artigos/GT6-966-60320100901153457.pdf>. Acesso em: 22 nov. 2015 
KASTRUP, V. O lado de dentro da experiência: atenção a si e produção de subjetividade humana numa oficina de cerâmica para pessoas com deficiência visual adquirida. Revista Psicologia: Ciência e profissão, Brasília, v.28, n.1, p.186-199, set. 2008.

KASTRUP, V. O funcionamento da atenção no trabalho do cartógrafo. In: PASSOS, E., KASTRUP, V.; ESCÓSSIA, L. (Orgs.). Pistas do método da cartografia: pesquisaintervenção e produção de subjetividade. Porto Alegre: Sulina, 2009. p. 32 -51

LARROSA, J. Pedagogia profana: danças, piruetas e mascaradas. Belo Horizonte: Autêntica, 2001.

LEFF, H. Complexidade, interdisciplinariedade e saber ambiental. In: PHILIPPI JR. A.; C. E. M. Tucci; D. J. Hogan; R. Navegantes. (Ed.). Interdisciplinaridade em ciências ambientais. São Paulo: Signus, 2000. p.19-51. Disponível em: $<$ http://www.dominiopublico.gov.br/pesquisa/DetalheObraForm.do?select_action=\&co_obra $=50281>$. Acesso em: 18 mai. 2011 .

LIMA, G. F. C. Crise ambiental, educação e cidadania: os desafios da sustentabilidade emancipatória. In: LOUREIRO, C. F. B.; LAYRARGUES, P. P.; CASTRO, R. S. (Orgs.). Educação ambiental: repensando o espaço da cidadania. São Paulo, Cortez, 2002. p. 115-148.

LOUREIRO, C. F. B. Educação ambiental e movimentos sociais na construção da cidadania ecológica e planetária. In: LOUREIRO, C. F. B. ; LAYRARGUES, P. P.; CASTRO, R. S. de. (Orgs). Educação ambiental: repensando o espaço da cidadania. São Paulo: Cortez, 2002. p.69-98.

MATURANA, H. Emoções e linguagem na educação e na política. Belo Horizonte: Ed. UFMG, 1998.

MAZZARINO, J. M. Entre poéticas e políticas: contribuições da educação ambiental para a educação formal e não formal. In: SEMINÁRIO NACIONAL FORMAÇÃO PEDAGÓGICA E PENSAMENTO NÔMADE: experimentações curriculares, 1, Lajeado, 2015. Lajeado: UNIVATES, 2015. Inserir p.49-49. Disponível em: <https://www.univates.br/editoraunivates/media/publicacoes/119/pdf_119.pdf> Acesso em: 22 nov. 2015.

MENDONÇA, R. Meio ambiente \& natureza. São Paulo: Editora Senac, 2012.

MUNHOZ, A. V. Práticas Investigativas: dos espaços aos saberes. Revista Interacções, Lisboa, n. 21, p. 190-203, 2012.

PASSETTI, E. Ecopolítica e controle por elites. In: PREVE, A. M.; CORRÊA, G. (Orgs.) Ambientes da ecologia: perspectivas em política e educação. Santa Maria: Editora UFSM, 2007. p.09-30.

PASSOS, E. ; BARROS, R. B. A cartografia como método de pesquisa-intervenção. In: ; KASTRUP, V.; ESCÓSSIA, L. (Orgs.). Pistas do método da cartografia: pesquisaintervenção e produção de subjetividade. Porto Alegre: Sulina, 2009. p. 17 - 31

ROLNIK, S. Cartografia sentimental: transformações contemporâneas do desejo. São Paulo: Estação Liberdade, 1989. 
SATO, M.; GAUTHIER, J. Z.; PARIGIPE, L. Insurgência do grupo pesquisador na educação sociopoiética. In SATO, M.; CARVALHO, I. Educação ambiental: pesquisa e desafios. Porto Alegre: Artmed, 2005. p. 99-118.

SERRES, M. A lenda dos anjos. São Paulo: Aleph, 1995.

SILVA, T. T. da. Dr. Nietzsche, curriculista - com uma pequena ajuda do professor Deleuze. In: CORAZZA, S.; SILVA, T. T. da. (Orgs.). Composições. Belo Horizonte: Autêntica, 2003. p.35 -57

SILVEIRA, E. A arte do encontro: a educação estética ambiental atuando com o teatro do oprimido. Educação em Revista, Belo Horizonte, v. 25. n. 3, p.369-394, Dez. 2009. Disponível em: <http://www.scielo.br/pdf/edur/v25n3/18.pdf〉. Acesso em: 13 jan. 2014.

TRISTÃO, M. Rede de relações: os sentidos da educação ambiental na formação de professores/as. 2001. 270f. Tese (Doutorado em Educação) - Programa de Pós-Graduação em Educação, Universidade de São Paulo, São Paulo, 2001.

VARGAS, A. Projeto Camaleão. 2009. 07f. Trabalho apresentado como requisito parcial para conclusão da Disciplina de Prática Investigativa III, Curso de Pedagogia, Centro Universitário UNIVATES, Lajeado, 2009. 